\title{
Severe pulmonary arterial hypertension in a patient with small ventricular septal defect
}

\author{
Narayanapillai Jayaprasad, Suresh Madhavan
}

Department of Cardiology, Government Medical College, Kottayam, Kerala, India

\section{Correspondence to} Dr Narayanapillai Jayaprasad, jayaprasadn@gmail.com

Accepted 30 December 2016

CrossMark

To cite: Jayaprasad N, Madhavan S. BMJ Case Rep Published online: [please include Day Month Year] doi:10.1136/bcr-2016218972

\section{DESCRIPTION}

A boy aged 16 years presented to our hospital with a history of dyspnoea on exertion and haemoptysis. His cardiovascular examination revealed features of severe pulmonary artery hypertension (PAH). He had no cyanosis. His transthoracic echocardiogram showed dilated right atrium and ventricle with the interventricular septum bulging to the left side. There was a small perimembraneous ventricular septal defect (VSD) with right-to-left shunt (figure 1 and video 1 ). The left atrium and ventricle were of normal size. Continuous wave Doppler evaluation showed right-to-left shunting with a peak gradient of $33 \mathrm{~mm} \mathrm{Hg}$, thus indicating suprasystemic PAH. Doppler evaluation of the

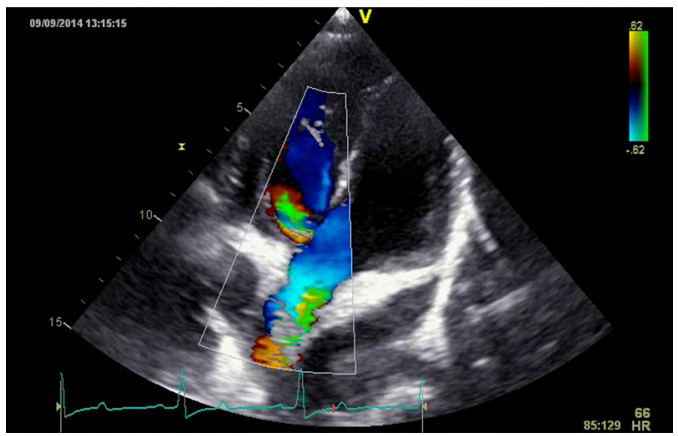

Video 1 Transthoracic echocardiogram apical five-chamber view showing the right-to-left shunt through ventricular septal defect.

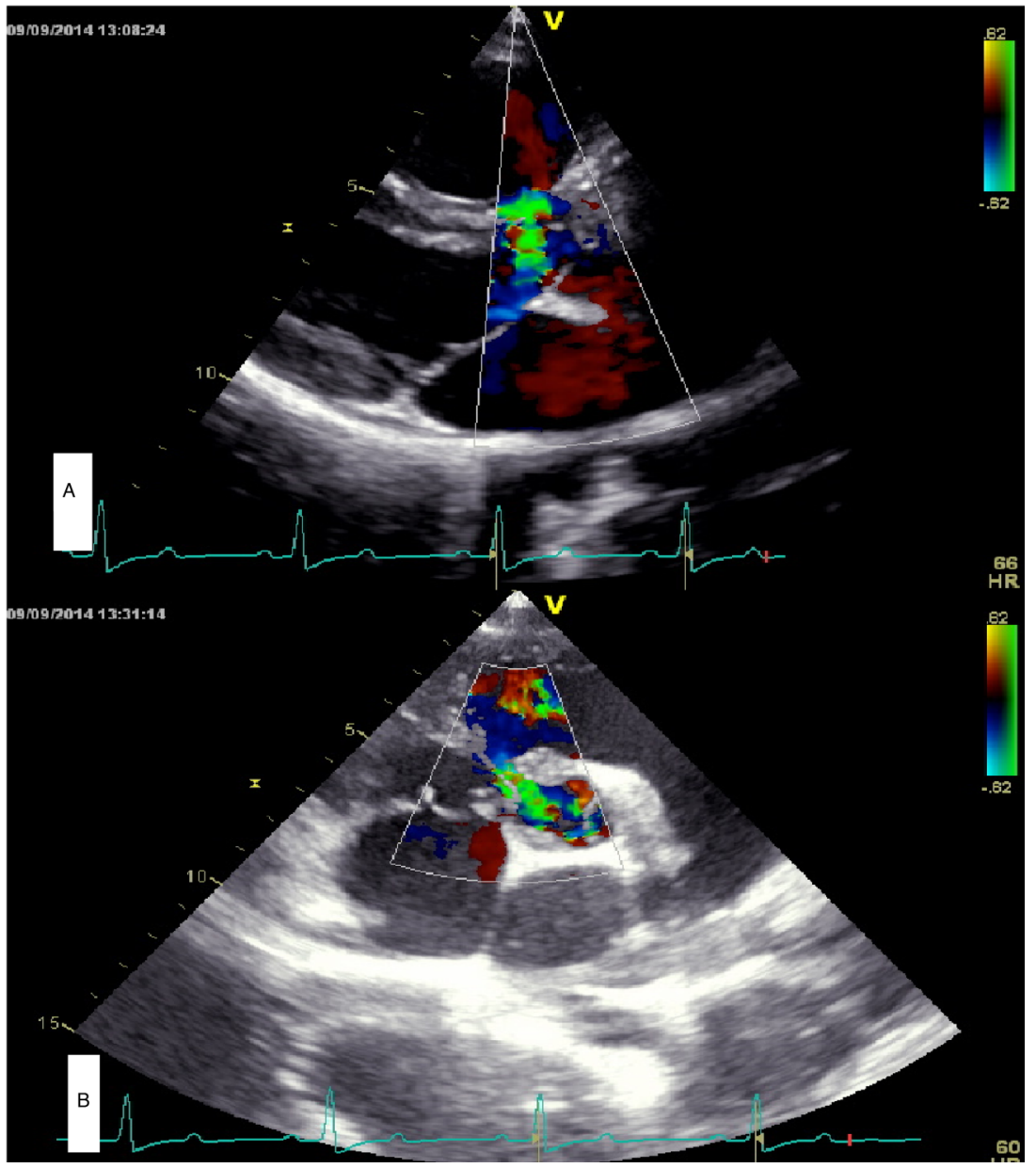

Figure 1 Transthoracic echocardiogram: (A) parasternal long-axis view showing small perimembraneous ventricular septal defect (VSD) and the right-to-left shunt. (B) Parasternal short-axis view showing $2 \mathrm{~mm}$ subaortic VSD. 


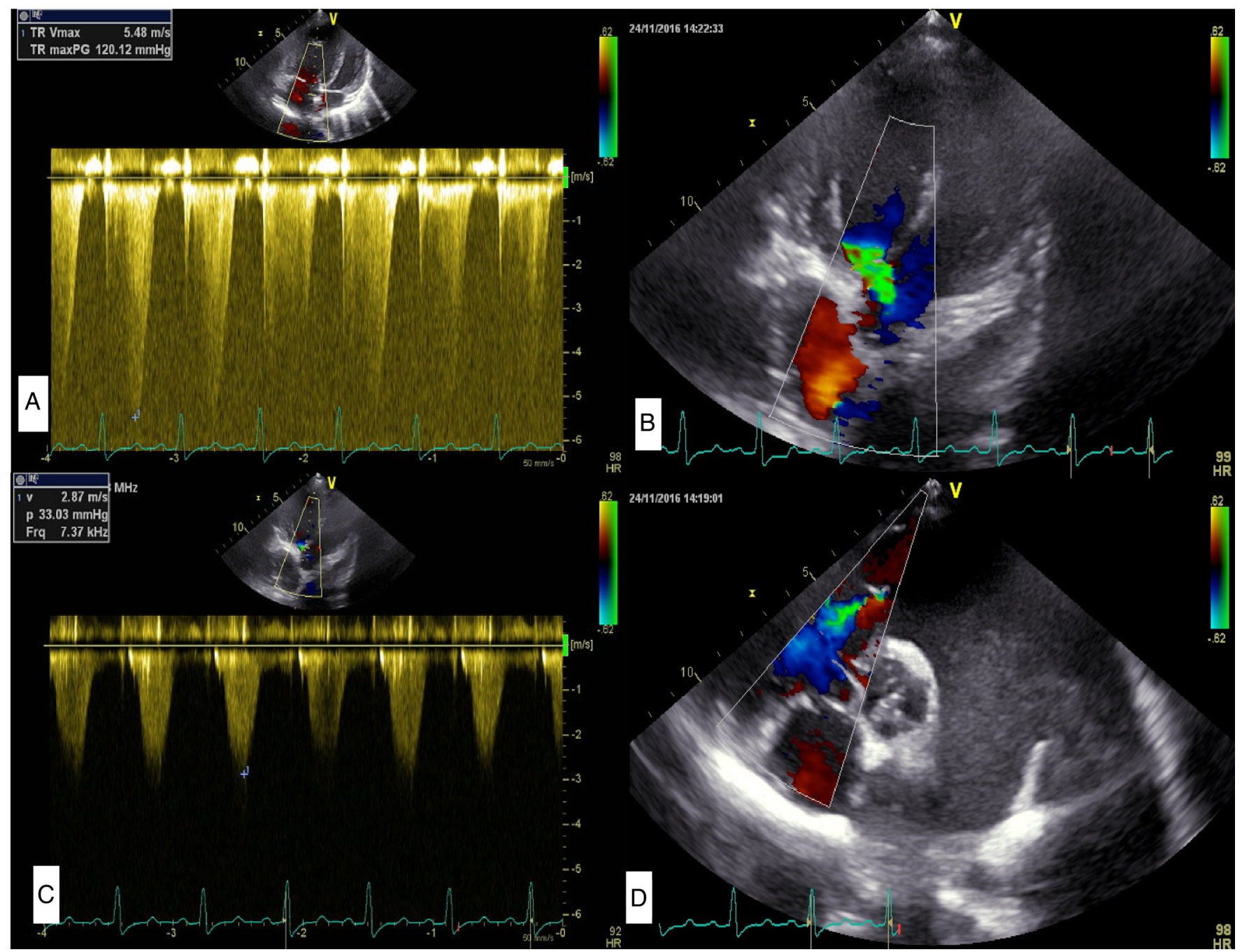

Figure 2 Transthoracic echocardiogram (A) Continuous wave (CW) Doppler evaluation of tricuspid regurgitation (TR) showing TR peak gradient of $120 \mathrm{~mm} \mathrm{Hg}$. (B) CW Doppler showing the right-to-left shunt with a gradient of $33 \mathrm{~mm} \mathrm{Hg}$. (C) Apical five-chamber view showing the right-to-left shunt. (D) Parasternal short axis showing hugely dilated pulmonary artery with spontaneous echocontrast and pulmonary regurgitation.

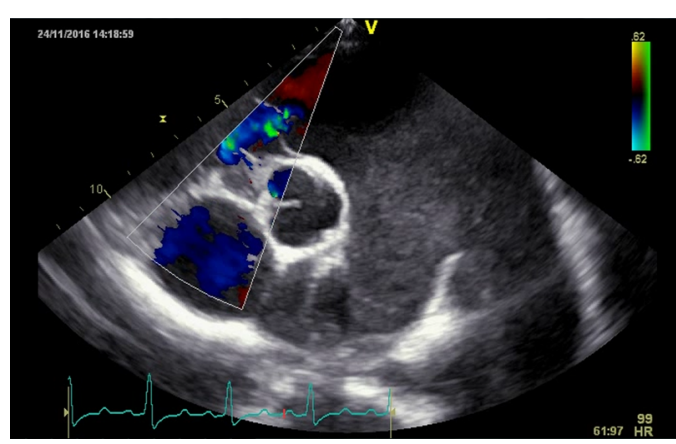

Video 2 Grossly dilated pulmonary artery with spontaneous echocontrast and pulmonary regurgitation.

tricuspid regurgitation (TR) jet showed a gradient of $120 \mathrm{~mm} \mathrm{Hg}$ (figure 2). The pulmonary artery (PA) was hugely dilated with spontaneous echocontrast, but no thrombus (figure 2 and video 2). In spite of extensive evaluation, we could not find a secondary cause for pulmonary hypertension in this patient and PAH was presumed to be idiopathic or primary PAH superimposed on a small VSD. He was treated with a combination of phosphodiesterase inhibitor sildenafil and endothelin inhibitor ambrisentan. Severe PAH has been described in small VSD ${ }^{1}$ and after spontaneous closure of VSD. ${ }^{2}$ In those cases, initially, VSD was large enough to initiate pulmonary vascular disease. In our case, we think that the two pathologies are coincidental, as there were no clinical features of a large VSD at any time.

\section{Learning points}

- The presence of congenital heart disease may be pathologically irrelevant in many patients as in our case where the lesion is haemodynamically insignificant.

- The patient should be evaluated for a secondary cause including thromboembolic pulmonary artery hypertension in such a case.

- The velocity and direction of flow across the small ventricular septal defect could actually be useful in monitoring the natural history or response to medication in this patient. 
Contributors Both the authors are actively involved in the conception and design, acquisition of data and writing up the manuscript.

Competing interests None declared.

Patient consent Obtained.

Provenance and peer review Not commissioned; externally peer reviewed.

\section{REFERENCES}

1 Bisset GS, Hirschfeld SS. Severe pulmonary hypertension associated with a small ventricular septal defect. Circulation 1983;67:470-3.

2 Shem-Tov A, Fine LG, Rotem Y, et al. Occlusive pulmonary vascular disease in a child with a spontaneously closed ventricular septal defect. Isr J Med Sci 1973;9:469-76.

Copyright 2017 BMJ Publishing Group. All rights reserved. For permission to reuse any of this content visit http://group.bmi.com/group/rights-licensing/permissions.

BMJ Case Report Fellows may re-use this article for personal use and teaching without any further permission.

Become a Fellow of BMJ Case Reports today and you can:

- Submit as many cases as you like

- Enjoy fast sympathetic peer review and rapid publication of accepted articles

- Access all the published articles

- Re-use any of the published material for personal use and teaching without further permission

For information on Institutional Fellowships contact consortiasales@bmjgroup.com

Visit casereports.bmj.com for more articles like this and to become a Fellow 